\title{
Analysis of biorisk management practices in clinical \& research laboratories in major cities of KP Province, Pakistan
}

\author{
Hoor Shumail ${ }^{1}$, Izhar Ahmad ${ }^{2}$, Shah Khalid ${ }^{2 *}$, Tayyab Rehman ${ }^{3}$, \\ Maqsood Anwar ${ }^{2}$ and Syed Inzimam Ul Haq ${ }^{2}$ \\ 1. Women University Mardan, KPK-Pakistan \\ 2. Department of Botany, Islamia College Peshawar, KPK-Pakistan \\ 3. Department of Molecular Biology \& Genetics, Institute of Basic Medical Sciences, Khyber Medical University, \\ Peshawar, KPK-Pakistan \\ *Corresponding author's email: shahkhalid@icp.edu.pk
}

Citation

Hoor Shumail, Izhar Ahmad, Shah Khalid, Tayyab Rehman, Maqsood Anwar and Syed Inzimam U1 Haq. Analysis of biorisk management practices in clinical \& research laboratories in major cities of KP Province, Pakistan. Pure and Applied Biology. Vol. 9, Issue 3, pp2082-2087. http://dx.doi.org/10.19045/bspab.2020.90222

\begin{tabular}{llll}
\hline \hline Received: 30/03/2020 & Revised: 29/05/2020 & Accepted: 01/06/2020 & Online First: 15/06/2020 \\
\hline
\end{tabular}

\section{Abstract}

Biosecurity is the protection, control and accountability of biological agents and toxins within laboratories, in order to prevent their loss, theft, misuse, unauthorized access or intentional unauthorized release. Laboratories are responsible for biosafety and biosecurity that protects their workers, animal population, and the environment from exposure or spread of pathogens they come across with. The purpose of this preliminary study was to collect data in order to assess and evaluate the measures being taken for biosafety and biosecurity in clinical diagnostic and research labs. Visits to the sites were prescheduled and in some cases were informal and unscheduled with the hope to get a clear picture of the practices. A detailed observational survey and unwritten questions were used to elicit information. The focus was on laboratory licensing system, infrastructure, administration, quality assurance, collection, handling, processing, storage and transportation of clinical samples, waste disposal, Lab records, access to bio hazardous materials and security checks on pathogens, researchers and workers. Based on Standard BRM Guidelines, maximum numbers of the labs were below minimum required standard and were categorized as BSL-0. Variety of BSL-2 and BSL-3 category bacterial and viral pathogens were easily assessable and, therefore, were isolated and identified in our lab. We conclude that lab management is lacking at all levels. It is recommended that biosecurity concerns be conveyed to all stakeholders for designing and implementing action plan.

Keywords: Biosafety; Biosecurity; Clinical labs; Research labs

\section{Introduction}

Bio risk management includes the development of various ways and strategies to reduce and controls the risks related to biological agent [1]. This can be achieved by broadly dividing bio risk management into biosafety and biosecurity. Biosafety includes the basic principles and practices implemented in a laboratory to restrict accidental exposure and release of pathogens and toxins [1-3]. Whereas, biosecurity includes the protection, control and 
accountability of important biological materials such as pathogens, toxins, vaccines, genetically modified organisms, genetic elements and clinically important samples inside laboratories to prevent their loss, theft, misuse, unauthorized access or intentional unauthorized release [4-6]. Laboratories are basic and obligatory part of healthcare systems and research institutions. Many public and private sector laboratories including clinical, hospital, public health and academic laboratories promote improvement in health care and public health through their research and diagnostic activities [7]. Various activities including samples analysis, disease diagnosis, experiments including pharmaceutical development of novel drugs, epidemiological studies, and scientific research takes places in biological laboratories in public and private sectors. Numerous types of biological materials including pathogens, toxins, chemicals, genetically modified organisms are handled in laboratories all over the world for various experimental and diagnostic purposes [8-10]. It is the responsibility of laboratory personnel to minimize the exposure of community to these risks by follow safe working protocols in order to keep biological samples and materials safe and secure. In the recent past, pathogens and toxins have been used to harm and threaten societies. A basic approach in reducing theses hazards is by conducting risk assessment of biological agents, chemicals and protocols followed while working in laboratories $[10,11]$. Day by day increasing biological threat from emerging and reemerging infectious diseases and bioterrorism, it is an essential need for the government and agencies around the world to increase awareness among researchers and laboratory personnel for identification, handling, storage and preservation of these agents.

\section{Materials and methods}

This preliminary survey was carried out from March to August 2019, focusing clinical/ diagnostic and academic/ research labs of Peshawar, Mardan and Charsadda (Fig. 1). A total of 337 labs (Table 1) were assessed for bio risk assessment. The information elicited during the visits were about the type of samples, collection, storage, transportation, pathogen type, pathogen storage, processing and discarding pathogens and recording data. Besides, information on administrative control such as policy or SOP's and training of staff was recorded. Moreover, lab personnel, practice, procedures, use of PPE, lab equipments, incident management and waste management were focused. Biosecurity risk assessment was the main purpose of this study. Information about physical security, personal management, material control, and accountability, transport and information security were focused. The information collected was based on observation and unwritten questions. In many laboratories we easily managed to collect pathogen containing waste, discarded samples from unlabeled dustbins. The purpose was to check the presence of pathogens. The samples were brought to the laboratory and were identified using biochemical and molecular techniques.

\section{Results}

\section{Bio risk Assessment}

More than three hundred labs (337) of both public and private sectors of clinical/diagnostic and academic/research purposes were assessed for bio risk assessment. Bio risk was assessed for biosafety and biosecurity using appropriate parameters and guidelines provided by WHO. Based on these parameters the collected data was further divided in three different tables.

\section{Biosafety}

All facilities whether public sector or private sector that deals with pathogenic and hazardous materials have to implement basic biosafety parameters. In this survey majority 
of the labs were not following standard protocols for bio risk management. The collected data about the biosafety parameters is summarized in (Table 2). All of the labs visited during the study including clinical and research laboratories were not following strict biosafety guidelines. About $85 \%$ of the laboratory personnel were not even aware of the high risk associated with pathogens they were handling, the pathogens and toxins were not properly labeled, some of them were working without following standard operating procedures. Most of the lab personnel were not using personal protections equipment's during working with pathogens.
Aside from this most of the workers in lab were handling pathogens in open air without any safety cabinet. Records of all the samples present and preserved in labs were easily assessable. Those laboratories dealing with just blood samples were disposing of the samples directly in drainage system, aside from this in academic institutes the students and researchers were unaware of the basic concepts of biosafety and biosecurity. Incinerators were not available in majority of public sector labs while in some high reputed hospitals incinerators were not in working condition.

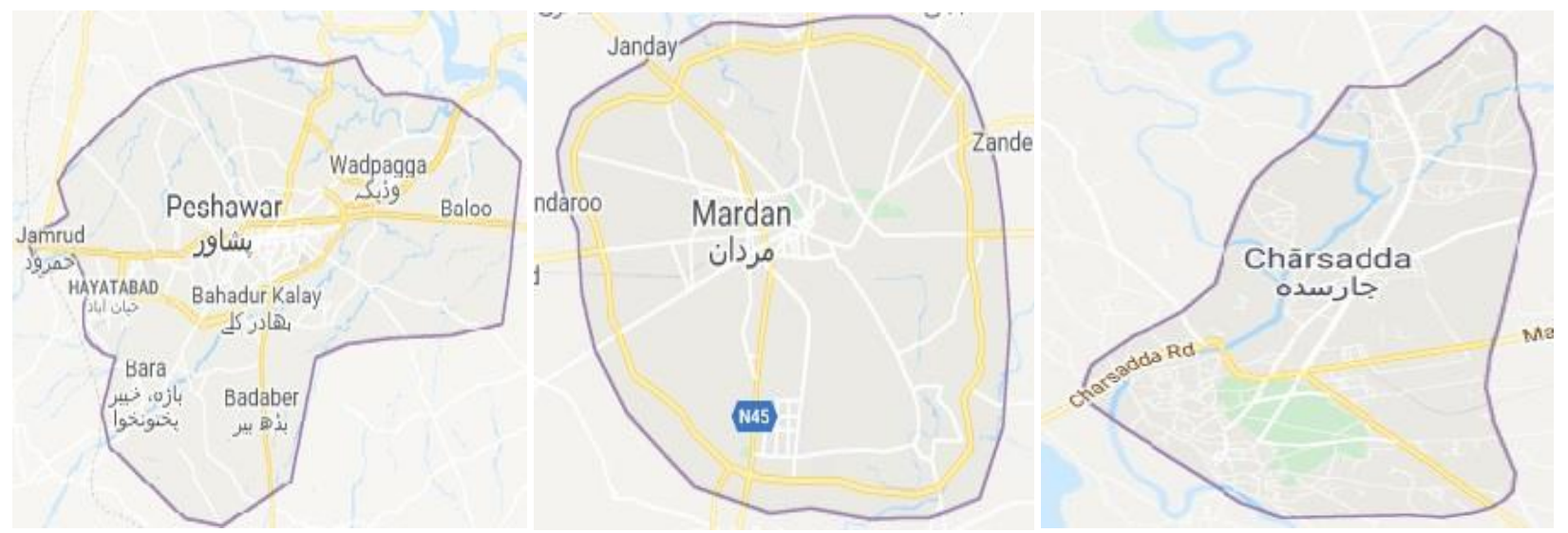

Figure 1. Map of Peshawar, Mardan and Charsadda. Source Google Map Satellite Image

Table 1. Location and Number of Labs

\begin{tabular}{|c|c|c|c|c|c|c|}
\hline \multirow{3}{*}{ S. No. } & & \multirow{3}{*}{ Location } & \multicolumn{4}{|c|}{ Number of Labs } \\
\hline & & & \multicolumn{2}{|c|}{$\begin{array}{c}\text { Clinical/Diagnostic } \\
\text { Labs }\end{array}$} & \multicolumn{2}{|c|}{$\begin{array}{c}\text { Academic/Research } \\
\text { Labs }\end{array}$} \\
\hline & & & $\begin{array}{l}\text { Public } \\
\text { sector }\end{array}$ & $\begin{array}{l}\text { Private } \\
\text { sector }\end{array}$ & $\begin{array}{l}\text { Public } \\
\text { sector }\end{array}$ & $\begin{array}{l}\text { Private } \\
\text { sector }\end{array}$ \\
\hline \multirow[t]{4}{*}{1} & \multirow{4}{*}{$\sum_{\substack{2 \\
2}}^{a}$} & Cantt area & _- & 17 & _ & _ \\
\hline & & $\begin{array}{l}\text { City area } \\
\text { a) Central Peshawar city } \\
\text { b) Dabgari garden }\end{array}$ & $\begin{array}{l}7 \\
-\end{array}$ & $\begin{array}{c}56 \\
117\end{array}$ & - & - \\
\hline & & University Town & 7 & 22 & 4 & 3 \\
\hline & & Hayatabad town & 2 & 8 & 1 & 4 \\
\hline 2 & & MARDAN & 3 & 42 & 3 & - \\
\hline \multirow[t]{3}{*}{3} & & CHARSADDA & 2 & 37 & 2 & \\
\hline & & Total & 21 & 299 & 10 & $\overline{7}$ \\
\hline & & Sub Total & \multicolumn{4}{|c|}{337} \\
\hline
\end{tabular}


Table 2. The results of biosafety assessment

\begin{tabular}{|c|c|c|}
\hline \multirow{2}{*}{ Bio risk Assessment } & \multicolumn{2}{|c|}{ Number of Labs } \\
\cline { 2 - 3 } & Satisfactory* $^{*}$ & Un-Satisfactory \\
\hline Sample Handling & $30 \%$ & $70 \%$ \\
\hline Pathogen Handling & $15.3 \%$ & $85 \%$ \\
\hline SOP's & $45 \%$ & $54.4 \%$ \\
\hline Training of lab workers & $27 \%$ & $73 \%$ \\
\hline Use of PPE & $5.2 \%$ & $95 \%$ \\
\hline Lab equipment's & $13 \%$ & $87 \%$ \\
\hline Incident Management & $35 \%$ & $65.3 \%$ \\
\hline Waste Management & $4 \%$ & $96 \%$ \\
\hline Recording of Information & $56.4 \%$ & $43.5 \%$ \\
\hline Pathogen Record & $18 \%$ & $82 \%$ \\
\hline
\end{tabular}

*Biosafety level was considered satisfactory in those labs who followed the basic biosafety guidelines provided by WHO. (Lab biosecurity guidelines, Sept, 2006 WHO/CDS/EPR/2006.6)

\section{Biosecurity}

The main purpose of this survey was look deeply into the biosecurity practices being followed in laboratories in Peshawar. Biosecurity assessment is the basic step in implementing an effective biosecurity system in labs as securing pathogens and toxins is a different task from securing other chemicals present in lab. The data collected during this survey regarding biosecurity practices is summarized in (Table 3). The first and basic parameter of biosecurity i.e. physical biosecurity was found inadequate in majority of labs as, locks and security cameras were installed in some of the labs but most of the cameras were not in working conditions and were not monitored. Fences and grills on windows were present in some of the labs. Intrusion alarms were not installed in any lab due to which the labs were easily assessable by anyone.

Table 3. Satisfaction level in Lab biosecurity

\begin{tabular}{|c|c|c|c|}
\hline \multirow{2}{*}{ S. No. } & \multirow{2}{*}{ Bio risk Assessment } & \multicolumn{2}{|c|}{ No of Labs } \\
\cline { 3 - 4 } & Physical Security & Satisfactory* & Un-Satisfactory \\
\hline \multirow{1}{*}{ a) Graded Protection } & $16 \%$ & $84 \%$ \\
& b) Detect/Delay/Response & $13 \%$ & $87 \%$ \\
\hline \multirow{2}{*}{} & Personal Management & & \\
& a) Personnel Training & $23 \%$ & $75 \%$ \\
& b) Security Awareness & $37 \%$ & $63 \%$ \\
\hline $\mathbf{3}$ & Material Control and accountability & $11 \%$ & $89 \%$ \\
\hline $\mathbf{4}$ & Transport Security & $4 \%$ & $96.3 \%$ \\
\hline
\end{tabular}

*Biosafety level was considered satisfactory in those labs who followed the basic biosafety guidelines provided by WHO. (Lab biosecurity guidelines, Sept, 2006 WHO/CDS/EPR/2006.6)

High risk pathogens were easily assessable in some of high reputed tertiary care hospitals of Peshawar. Files and records of extremely high risk pathogens (BSL-3, 4) were kept in lock and were not approachable to anyone without proper permission from management. While records of other pathogens were easily available. Most of the students and researchers were disposing of high risk pathogenic samples directly in the drainage 
system after completing their experiments. While some of them in spite of properly burring the pathogens after decontamination; were throwing used culture plates in garbage cans without proper decontamination. Highly pathogenic organisms (Table 4) were found in the samples collected from these clinical and research labs which suggests that the pathogens were disposed of in the environment without proper decontamination.

Table 4. Pathogens identified

\begin{tabular}{|c|}
\hline Name of Pathogen \\
\hline Salmonella Typhi \\
\hline Mycobacterium Tuberculosis \\
\hline E.coli \\
\hline Staphylococcus aureus \\
\hline MRSA \\
\hline Klebsiella pneumoniae \\
\hline Pseudomonas aeruginosa \\
\hline HAV \\
\hline HBV \\
\hline HCV \\
\hline
\end{tabular}

\section{Discussion}

Biorisk management is an emerging concept globally due the increased number of emerging, remerging and highly resistant pathogens taking lives of millions of people all over the world. It was important to observe the current status of biosafety and biosecurity in clinical and research laboratories of Peshawar, Mardan and Charsadda. Biosafety and biosecurity are the terms, the global scientific communities are becoming aware of due to the workshops, trainings and seminars being arranged by different organizations. The purpose of this study was to summarize the current status of bio risk management practices being carried out in major cities of KP. As opposed to a previous study conducted in countries where most of the labs were following simple biosecurity measure [12], we are lacking even the basic biosecurity parameters in majority of our labs including labs of some high reputed public sector hospitals. This would help in future to develop strategies to overcome these gaps by arranging workshops and trainings on implementing bio risk management practices. This survey revealed the negligence level of biosecurity measures in clinical and research settings. Workshops, trainings and seminars are required to be arranged on emergency basis to introduce and implement the guidelines of bio risk management $[13,14]$. As suggested previously Literature about the proper handling of biological samples including pathogens and toxins should be developed and distributed among laboratories [15]. In addition to this, extraordinary measures are required to be taken as soon as possible as the pathogens which are disposed off in environment without any proper decontamination are the main cause of alarmingly increasing infectious diseases in local community specially hepatitis. Thus biosafety and biosecurity measures should be implemented as mandatory as soon as possible with the development of a regulatory committee that defines and establishes guide lines for bio risk management.

\section{Conclusion}

This study touches upon the current scenario of biosecurity in clinical and research labs of both public and private sectors. This survey identified in most of the labs, basic concept of biosecurity is not understood by lab staff, 
including students and researches. This survey draws attention towards the alarming situation of biosecurity in the major cities of Khyber Pakhtunkhwa province of Pakistan. Its recommended that government and policy makers should introduce some measures for the implementation of biosecurity measures in labs on urgent basis. Training workshops regarding awareness of bio risk management and constitution of a survey and regulatory committee are some other steps that could improve the current scenario of biosecurity of labs.

\section{Authors' contributions}

Conceived and designed the experiments: $\mathrm{H}$ Shumail, I Ahmad \& S Khalid, Analyzed the data: T Rehman, M Anwar \& SIU Haq, Wrote the paper: H Shumail \& S Khalid.

\section{References}

1. WHO (2012). Laboratory Biorisk Management: Strategic Framework for Action 2012-2016 Retrieved from WHO/HSE/2012.3.

2. Sijnesael PCC, Berg LM, Bleijs DA, Odinot P, Hoog C, Jansen MWJC, Kampert E, Rutjes SA, Broekhuijsen C \& Banus S (2014). Novel dutch selfassessment biosecurity toolkit to identify biorisk gaps and to enhance biorisk awareness. Front Public Health 2:197.

3. Kagirita AA, Owalla TJ, Okwalinga P, Opio J, Baguma A, Mugasha R, Kakooza F, Ojwiya A, Aisu S, Eragu R, Ikoba S, Nabadda S, Musinguzi KA \& Atwine D (2018). Biorisk Management Practices in Public and Private Laboratories in Uganda: A Nationwide Baseline Survey. $J$ Bioterror Biodef 9(3): 164.

4. Dickmann P, Sheeley H \& Lightfoot N (2015). Biosafety and Biosecurity: A Relative Risk-Based Framework for Safer, More Secure, and Sustainable Laboratory Capacity Building. Front Public Health 3.

5. Bakanidze LG, Tsanava SA \& Tsertsvadze NS (2010). Biosafety and Biosecurity in Georgia: New Challenges. Appl Biosaf 15(2): 85-88.
6. Boykin LM, Armstrong KF, Kubatko L \& Barro PD (2012). Species delimitation and global biosecurity. Evol Bioinform 8: 1-37.

7. Reller LB, Weinstein MP, Peterson LR, Hamilton JD, Baron EJ, Tompkins LS, Miller JM, Wilfert CM, Tenover FC \& Thomson RB (2001). Role of Clinical Microbiology Laboratories in the Management and Control of Infectious Diseases and the Delivery of Health Care. Clin. Infect. Dis 32(4): 605-610.

8. WHO (2006). Biorisk management: Laboratory biosecurity guidance. Retrieved from WHO/CDS/EPR/2006.6.

9. Fournier PE, Drancourt M, Colson P, Rolain JM, La Scola B \& Raoult D (2013). Modern clinical microbiology: new challenges and solutions. Nat Rev Microbiol 11(8): 574-585.

10. Oladeinde $\mathrm{BH}$, Omoregie R, Odia I, Osakue EO \& Imade OS (2013). Biorisk assessment of medical diagnostic laboratories in Nigeria. Saf Health Work 4(2): 100-104.

11. Gentilli SM, Potts JM, Clarkson AJ \& Jacobi HB (2016). An Overview of the NIH Biorisk Management Program. Appl Biosaf 21(1): 26-33.

12. Gaudioso J \& Zemlo T (2007). Survey of Bioscience Research Practices in Asia: Implications for Biosafety and Biosecurity. Appl Biosaf 12(4): 260-267.

13. Shafaq H, Qureshi S \& Shakoor S (2016). Improving Biosecurity in Pakistan: Report from an IATA Guidelines Training for Transportation of Biological Agents. Int $J$ Infect Dis 53: 54-55.

14. Franz DR (2019). Facilities, equipment and procedures: An historic glimpse at high-containment lab safety and security. Journal of Biosafety and Biosecurity 1(2): 98-99.

15. Qasmi SA, Khan E \& Maqbool AZ (2012). Survey of Biorisk Management in Clinical Laboratories in Karachi, Pakistan. Appl Biosaf 17(4): 198-207. 